\title{
PLOS $\mid$ submission
}

S9 Table Schizophrenia association chi-squared general linear model coefficients for tissuespecific eQTLs with different functional affiliations upon exclusion of CommonMind and GTEx brain eQTLs. The test statistics refer to the respective interaction terms. The interaction with TotLD represents the enrichment ascribable to the eQTLs irrespective of their LD-tagging power. Enhancer and Promoter affiliations were assigned by Roadmap in the corresponding tissues.

\begin{tabular}{|c|c|c|c|c|c|}
\hline & annotation & $\bar{\beta}$ & $\beta$ (95\% low) & $\beta$ (95\% high) & $p$ \\
\hline \multirow{10}{*}{ Adipose eQTL } & TotLD & 0.0073 & -0.028 & 0.042 & 0.72 \\
\hline & Exon & 0.025 & -0.012 & 0.062 & 0.23 \\
\hline & Intron & 0.008 & -0.029 & 0.045 & 0.71 \\
\hline & X5UTR & -0.017 & -0.055 & 0.02 & 0.42 \\
\hline & X3UTR & -0.06 & -0.10 & -0.02 & 0.0085 \\
\hline & Active_Promoter & -0.10 & -0.36 & 0.16 & 0.50 \\
\hline & Weak_Promoter & -0.044 & -0.21 & 0.13 & 0.65 \\
\hline & Strong_Enhancer & -0.017 & -0.16 & 0.13 & 0.83 \\
\hline & Weak_Enhancer & -0.15 & -0.33 & 0.026 & 0.13 \\
\hline & TotLD & 0.08 & 0.045 & 0.12 & $6.74 \mathrm{E}-05$ \\
\hline \multirow{8}{*}{ Epidermal eQTL } & Exon & 0.049 & 0.018 & 0.081 & 0.0062 \\
\hline & Intron & 0.046 & 0.009 & 0.083 & 0.029 \\
\hline & X5UTR & 0.028 & -0.0065 & 0.063 & 0.15 \\
\hline & X3UTR & -0.029 & -0.062 & 0.0037 & 0.12 \\
\hline & Active_Promoter & 0.045 & -0.15 & 0.24 & 0.68 \\
\hline & Weak_Promoter & 0.077 & -0.11 & 0.27 & 0.48 \\
\hline & Strong_Enhancer & 0.033 & -0.14 & 0.21 & 0.74 \\
\hline & Weak_Enhancer & -0.019 & -0.21 & 0.17 & 0.86 \\
\hline \multirow{9}{*}{ LCL eQTL } & TotLD & 0.019 & -0.017 & 0.055 & 0.35 \\
\hline & Exon & -0.019 & -0.051 & 0.013 & 0.30 \\
\hline & Intron & 0.0027 & -0.032 & 0.037 & 0.89 \\
\hline & X5UTR & -0.038 & -0.071 & -0.0057 & 0.04 \\
\hline & X3UTR & -0.023 & -0.057 & 0.01 & 0.22 \\
\hline & Active_Promoter & 0.056 & -0.10 & 0.21 & 0.53 \\
\hline & Weak_Promoter & -0.17 & -0.38 & 0.049 & 0.17 \\
\hline & Strong_Enhancer & 0.024 & -0.13 & 0.17 & 0.78 \\
\hline & Weak_Enhancer & 0.004 & -0.15 & 0.16 & 0.96 \\
\hline \multirow{9}{*}{ Whole blood eQTL } & TotLD & 0.072 & 0.018 & 0.12 & 0.018 \\
\hline & Exon & -0.014 & -0.058 & 0.03 & 0.59 \\
\hline & Intron & 0.096 & 0.044 & 0.15 & 0.0012 \\
\hline & X5UTR & 0.087 & 0.034 & 0.14 & 0.0039 \\
\hline & X3UTR & -0.14 & -0.18 & -0.093 & $1.98 \mathrm{E}-08$ \\
\hline & Active_Promoter & -0.0093 & -0.56 & 0.54 & 0.98 \\
\hline & Weak_Promoter & 0.16 & -0.07 & 0.39 & 0.22 \\
\hline & Strong_Enhancer & 0.029 & -0.23 & 0.29 & 0.85 \\
\hline & Weak_Enhancer & -0.11 & -0.42 & 0.21 & 0.55 \\
\hline
\end{tabular}

